\title{
A Comparison of the Growth Characteristics of Arthrospira platensis in Deep Ocean Water, Surface Ocean Water, and Artificial Ocean Water
}

\author{
Yen Lee ${ }^{1^{*}}$, Ting-Mao Yang2 ${ }^{2}$ Jenn-Hung $\mathrm{Hsu}^{3}$ \\ ${ }^{1}$ Department of Life Science, National Taitung University, Taiwan \\ ${ }^{2}$ Katec R \& D Corporation, Taitung Branch, Taiwan \\ ${ }^{3}$ Center for General Education, National Taitung University, Taiwan \\ Email: *yenlee@nttu.edu.tw
}

Received 1 October 2015; accepted 19 October 2015; published 26 October 2015

Copyright (C) 2015 by authors and OALib.

This work is licensed under the Creative Commons Attribution International License (CC BY). http://creativecommons.org/licenses/by/4.0/

(c) (i) Open Access

\section{Abstract}

The use of deep ocean water (DOW) for cooling purposes, as drinking water (after desalination), and in algae cultures has increased in recent years in Taiwan. This study evaluates the growth performance of Arthrospira platensis in deep ocean water (DOW), surface ocean water (SOW), and artificial ocean water (AOW) with and without a supplementary medium (BG-11). During a 14-day growth period, $A$. platensis had the shortest generation time (5.22 \pm 0.38 days) and the highest average daily biomass yield of $0.083 \pm 0.007 \mathrm{~g} / \mathrm{L}$ (dry weight) in the DOW medium without supplementary BG-11. A. platensis had significant better growth rates when cultured in AOW with BG-11 than in SOW without BG-11. However, $A$. platensis growth rates did not differ $(p>0.05)$ when cultured in AOW and DOW with BG-11. The results revealed that DOW without supplementary BG-11 is a superior medium for culturing $A$. platensis.

\section{Keywords}

Deep Ocean Water, A. platensis, Growth Rate, Surface Ocean Water, Artificial Ocean Water

Subject Areas: Microbiology

\section{Introduction}

Deep ocean water (DOW) refers to water drawn from a depth of more than 200 meters and thus is not exposed ${ }^{*}$ Corresponding author.

How to cite this paper: Lee, Y., Yang, T.-M. and Hsu, J.-H. (2015) A Comparison of the Growth Characteristics of Arthrospira platensis in Deep Ocean Water, Surface Ocean Water, and Artificial Ocean Water. Open Access Library Journal, 2: e1984. http://dx.doi.org/10.4236/oalib.1101984 
to sunlight. Deep ocean water, which accounts for $95 \%$ of all sea water, is characterized by low temperatures, abundant nutrients (minerals, salts) and few pathogens, and is not contaminated with anthropogenic chemicals [1]-[3]. At depth of 700 meters, DOW has nitrate and phosphate concentrations of $12-18 \mathrm{mmol} / \mathrm{m}^{3}$ and $0.7-2.5$ $\mathrm{mmol} / \mathrm{m}^{3}$, respectively. Surface ocean water (SOW) is characterized by nitrate and phosphate concentrations of $0.1-1 \mathrm{mmol} / \mathrm{m}^{3}$ and $0.4-0.5 \mathrm{mmol} / \mathrm{m}^{3}$, respectively [4].

Upwelling of DOW occurs in oceans throughout the world. Although upward water constitutes no more than $0.5 \%$ of all sea water, it supports nearly $50 \%$ of all sea life [2]. Research on the applications of DOW is being conducted in the USA (Hawaii), Japan, Korea and Taiwan. Such applications include air conditioning, aquaculture and agriculture products, marine biotechnological pharmaceuticals, fresh water, strategic minerals, methanol and hydrogen fuel and many more [5] [6]. Taiwan has established five DOW pumping factories located in Hua-Lien Prefecture (three facilities) and Taitung Prefecture (two facilities). The Taitung DOW Research Center in Taiwan has the capacity to pump 12,000 tons of DOW per day. The system takes in DOW and uses it for cooling after which it is desalinated and used as drinking water. A small part is used to culture probiotics such as Lactobacillus acidophilus, Bacillus subtilis var. Natto, and Enterococcus faecium. A large proportion of the remaining DOW is then used for algae culture. A. platensis is being widely studied, not only for its nutritional attributes but also for its antioxidant, antimicrobial, anticancer and virus inhibition properties [7] [8]. This cyanobacterium was selected for mass culture at the Taitung DOW Research Center because it is rich in nutrients such as proteins (50\% - 70\%), lipids, vitamins, minerals, carbohydrates, and $\gamma$-linolenic acid [7] [9]-[12]. It also has high productivity, with a photosynthetic conversion rate of $8 \%-10 \%$ compared to only $3 \%$ in most terrestrial plants [13]. A. platensis can be used in the diets of fish, pigs, poultry, and even humans [11]. It is therefore imperative to investigate the effect of these differences between DOW and SOW media on growth performance of the cyanobacteria, Arthrospira platensis.

The nutrients contained in DOW are excellent for enhancing the productivity of the ocean environment [3]. The clean and stable water quality of DOW may also offer an ideal growth environment for A. platensis.

Sea water has a high concentration of calcium ions [14], which bind to algae cells (negatively charged) through an auto-flocculation process [15]. Mary-Leema et al. [16] pretreated sea water with $\mathrm{NaHCO}_{3}$ to precipitate the excess divalent cations and filtered the treated seawater to remove the precipitate. However, the objective of this study was to find out how well A. platensis grows in three different untreated ocean water media. We did not follow the procedures of Mary-Leema et al. [16] (in addition, it is difficult to pretreat and filter the large quantities of DOW).

A review of literature revealed that no comparative studies of A. platensis growth characteristics in AOW, DOW and SOW have been reported. This research is preliminary work for growing cyanobacteria in DOW on a large scale. The objective is to compare A. platensis growth characteristics in AOW, DOW and SOW media.

\section{Materials and Methods}

\subsection{Source of A. platensis}

Arthrospira platensis was purchased from Pingtung Fisheries Research Institute, Taiwan. This cyanobacterium was originally cultured and maintained in BG-11 medium ( $\mathrm{pH}$ 7.1) and dispensed from covered 20-liter transparent plastic tanks. The BG-11 medium was made up of $1.5 \mathrm{~g} / \mathrm{L} \mathrm{NaNO} 3,0.04 \mathrm{~g} / \mathrm{L} \mathrm{K}_{2} \mathrm{HPO}_{4}, 0.075 \mathrm{~g} / \mathrm{L} \mathrm{MgSO}{ }_{4} \cdot 7 \mathrm{H}_{2} \mathrm{O}$, $0.036 \mathrm{~g} / \mathrm{L} \mathrm{CaCl}{ }_{2} \cdot 2 \mathrm{H}_{2} \mathrm{O}, 0.006 \mathrm{~g} / \mathrm{L}$ citric acid, $0.006 \mathrm{~g} / \mathrm{L}$ ferric ammonium citrate, $0.001 \mathrm{~g} / \mathrm{L}$ EDTA (disodium salt), $0.02 \mathrm{~g} / \mathrm{L} \mathrm{Na}_{2} \mathrm{CO}_{3}, 1 \mathrm{~mL}$ trace metal mix A5, $10 \mathrm{~g} / \mathrm{L}$ agar. Trace metal mix A5 was made up of $2.86 \mathrm{~g} / \mathrm{L}$ $\mathrm{H}_{3} \mathrm{BO}_{3}, 1.81 \mathrm{~g} / \mathrm{L} \mathrm{MnCl}_{2} \cdot 4 \mathrm{H}_{2} \mathrm{O}, 0.222 \mathrm{~g} / \mathrm{L} \mathrm{ZnSO}_{4} \cdot 7 \mathrm{H}_{2} \mathrm{O}, 0.39 \mathrm{~g} / \mathrm{L} \mathrm{NaMoO}_{4} \cdot 2 \mathrm{H}_{2} \mathrm{O}, 0.079 \mathrm{~g} / \mathrm{L} \mathrm{CuSO}{ }_{4} \cdot 5 \mathrm{H}_{2} \mathrm{O}, 49.4$ $\mathrm{mg} / \mathrm{L} \mathrm{Co}\left(\mathrm{NO}_{3}\right)_{2} \cdot 6 \mathrm{H}_{2} \mathrm{O}$ [17]. An aquarium air pump $(110 \mathrm{~V}, 4.5 \mathrm{~W}, 50 \mathrm{HZ}, 4400 \mathrm{~mL}$ air $/ \mathrm{min})$ was used to provide air to each tank through a plastic tube containing a sterilized cotton ball. The tube reached the bottom of the tank and a micropore gas diffuser connected to the end of the tube was used to disperse the air bubbles [18]. The airflow also caused water circulation within the tank. Temperatures were at ambient outdoor levels, ranging between $18^{\circ} \mathrm{C}-36^{\circ} \mathrm{C}$. An incandescent light (1700 lux) was suspended $10 \mathrm{~cm}$ above each tank to provide supplemental continuous illumination.

\subsection{Sources of DOW, SOW, and the AOW Recipe}

Deep ocean water was obtained from the Taitung Deep Ocean Water Research Center, Water Resources Agency, Ministry of Economics, Executive Yuan, Taiwan. The DOW was pumped from about 700 meters below the 
ocean surface while the SOW was collected from the ocean surface at Taitung Tai-ma-li village coast (N $\left.22^{\circ} 35^{\prime 2} 24.07^{\prime \prime}, \mathrm{E} 121^{\circ} 0^{\prime} 27.99^{\prime \prime}\right)$. The SOW was filtered through a piece of $110 \mathrm{~mm}$ Advantec filter paper and stored at $4^{\circ} \mathrm{C}$. The $\mathrm{pH}$ of DOW and SOW were adjusted to 8.4 with $0.1 \mathrm{M} \mathrm{NaOH}$ solution. Artificial ocean water was made according to the recipe of Pushparaj et al. (1995). The AOW medium was made up of $33.0 \mathrm{~g} / \mathrm{L} \mathrm{NaCl}$, $0.03 \mathrm{~g} / \mathrm{L} \mathrm{K}_{2} \mathrm{HPO}_{4}, 0.005 \mathrm{~g} / \mathrm{L}$ Fe-EDTA and Arnon's A-5 solution $(1 \mathrm{~mL} / \mathrm{L})$. Arnon's A-5 solution was made up of $\mathrm{H}_{3} \mathrm{BO}_{3}(0.99 \mathrm{mg} / \mathrm{L}), \mathrm{MnCl}_{2} \cdot 4 \mathrm{H}_{2} \mathrm{O}(1.00 \mathrm{mg} / \mathrm{L}), \mathrm{ZnSO}_{4}(0.18 \mathrm{mg} / \mathrm{L}), \mathrm{CuSO}_{4} \cdot 5 \mathrm{H}_{2} \mathrm{O}(0.04 \mathrm{mg} / \mathrm{L}),\left(\mathrm{NH}_{4}\right)_{6} \mathrm{Mo}_{7} \mathrm{O}_{24} \cdot 4 \mathrm{H}_{2} \mathrm{O}$ $(0.003 \mathrm{mg} / \mathrm{L})$, and $\mathrm{Na}_{3} \mathrm{VO}_{4} \cdot 16 \mathrm{H}_{2} \mathrm{O}(0.009 \mathrm{mg} / \mathrm{L})$ [19]. The $\mathrm{pH}$ of the AOW medium was also adjusted to 8.4. The A. platensis culture had a $\mathrm{pH}$ between 9.0 - 9.7 across all culture media. When the centrifuged wet weight of the cyanobacterium was added to any of the culture medium, the $\mathrm{pH}$ changed from 8.4 to about 9.0 - 9.1.

\subsection{Experimental Culture Conditions}

Since A. platensis was originally cultured in the BG-11 medium, two sets of ocean water media were prepared. BG-11 medium (without the trace elements to prevent heavy precipitation) was added to one set of ocean water media while the other set did not have BG-11 medium. For the first set, A. platensis was grown in three-liter loosely screw-capped Erlenmeyer flasks with $1000 \mathrm{~mL}$ of DOW, SOW or AOW only. Since A. platensis formed clumps regardless of growth medium, flasks were placed on a magnetic stir plate to mix the culture medium. Magnetic stir bars were adjusted to $150 \mathrm{rpm}$ and this effectively prevented the formation of cell clumps during the experimental period. All experiments were done indoors at ambient temperature. An energy saving light bulb (type: QIPU EF4R-36WD-EX, $120 \mathrm{~V}, 60 \mathrm{~Hz}, 36 \mathrm{~W}$ ) was hung $10 \mathrm{~cm}$ above the flasks and provided luminance of 5300 lux. The continuous light was necessary to promote high growth rates of A. platensis [12]. Each flask had an initial concentration of $A$. platensis of $2.0 \mathrm{~g} / \mathrm{L}$ wet weight, translating to $0.2 \mathrm{~g} / \mathrm{L}$ dry weight [20]. For the second set, A. platensis was also grown in three-liter screw cap Erlenmeyer flasks with $1000 \mathrm{~mL}$ of DOW, SOW, or AOW with added $1 \mathrm{~mL}$ concentrated (100×) BG-11 medium (equivalent to $0.1 \times$ concentration of BG-11 in each medium to prevent precipitation). These media with supplement were called $\mathrm{AOW}+$, SOW+, and DOW+ separately. All the other conditions were similar to those in set one. The A. platensis in both sets was allowed to grow for fifteen days. At the end of 15 days, cells were centrifuged (Hitachi Himac CR 22G) and a new growth cycle (with initial seeding amount $2.0 \mathrm{~g} / \mathrm{L}$ wet weight) was re-started under similar conditions as described above. This anthropic acclimatization process was done four times for each medium after which the acclimatized A. platensis cells were used for the growth characteristics experiment. A microscope was used to observe the A. platensis growth characteristics during the daily measurement of cyanobacteria biomass.

\subsection{A. platensïs Biomass Measurements}

Arthrospira platensis wet weight was obtained by centrifuging the culture at $5000 \mathrm{xg}$ for $5 \mathrm{~min}$. The supernatant was then discarded and the pellet washed once to remove the chemical load (from the nutrient medium) on the biomass and then centrifuged again before being weighed. The dry matter content of the pellet was assumed to be $10 \%$ [20].

Biomass concentration was also determined by optical density (OD) determination at $680 \mathrm{~nm}$ (CECIL $1020 \mathrm{~S}$ ) to produce a standard curve relating wet weight of A. platensis biomass to OD [20]-[23]. All results shown in this study represent means of three determinations \pm standard error of the OD measurements corresponding dry weight biomass.

\subsection{Generation Time}

Arthrospira platensis generation time was calculated by using the 14-day growth period (from the first day to the fifteenth day) biomass data from each culture medium. The specific growth rate is defined as the increase in cell mass per unit time, e.g., gram cells (g) per day. Specific growth rate can be calculated from the formula:

$$
\mu=\ln \left(X_{t 2} / X_{t 1}\right) / t_{2}-t_{1}\left[t_{2}>t_{1}\right]
$$

The specific growth rate is given by the symbol, $\mu$, where $X_{t 1}$ and $X_{t 2}$ are biomass measurements at the different time points, $t_{1}$ and $t_{2}$, respectively [24]. The "Doubling Time Calculator" [25] was also used.

\subsection{Average Daily Yield of the 14-Day Growth}

The average daily yields of $A$. platensis that grew in different media were calculated by subtracting the original 
seeding biomass (the $1^{\text {st }}$ day's weight) from the biomass at the fifteenth-day in each medium and dividing the result by the total growth period (14 days). Every medium was replicated 3 times, so the average and the standard deviation are presented.

\section{7. pH Values}

The $\mathrm{pH}$ values were measured daily during 14-day growth period using a Milwaukee $\mathrm{pH} 600 \mathrm{pH}$ meter. Three replicates were conducted.

\subsection{Statistical Analysis}

The study was designed to test the null hypothesis that growth of the cyanobacterium is not influenced by the different growth media during the culture period. All statistical analyses were done using the SPSS (version 21.0). The effect of different ocean water media on A. platensis growth was analyzed using two-way ANOVA. Where significant differences were detected, post-hoc Bonferroni test was done. Data presented are the mean of three independent measurements for each treatment. Significant levels for all analyses were set at $p<0.05$.

\subsection{Growth Curves and pH Daily Data Curve Drawing}

The A. platensis growth curves for different media and $\mathrm{pH}$ daily data curves were drawn by Microsoft Excel. All the data points were represented by the averages of three measurements.

\section{Results}

The $p$-value of the intergroup homogeneity test was 0.006 and the $F$-value was 3.354 . Post hoc tests were done and the results showed that when BG-11 was added to AOW the A. platensis growth rate was significantly better than A. platensis growth rate in SOW without supplement $(p=0.014)$. There were no significant differences in the growth rate of $A$. platensis when cultured in either BG-11 supplemented $(\mathrm{AOW}+, \mathrm{SOW}+$ and $\mathrm{DOW}+)$ or unsupplemented ocean water media (AOW, SOW and DOW). The $p$-values are listed in Table 1. The A. platensis growth rates in different media are shown in Figure 1.

\subsection{Generation Time}

Arthrospira platensis generation time was calculated by using the 14-day growth period biomass data from each culture medium (Table 2). The shortest generation time (5.22 \pm 0.38 days) for A. platensis was observed in DOW without BG-11 medium. Adding BG-11 medium to AOW and SOW reduced the generation times for $A$. platensis.

\subsection{Average Daily Yield of the 14-Day Growth}

Average daily biomass yield (mean $\pm \mathrm{sd}$ g/L, dry weight) was recorded as $0.071 \pm 0.003,0.054 \pm 0.006,0.083 \pm$

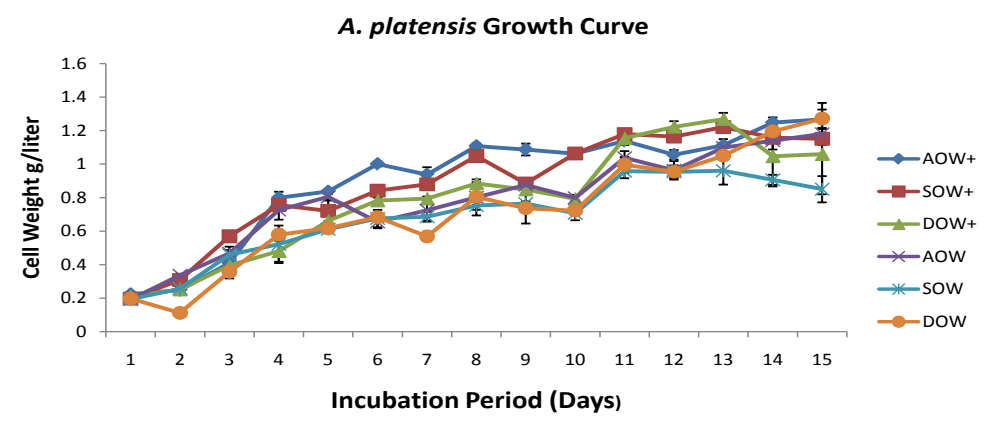

Figure 1. The growth curves for A. platensis cultured in six different media: artificial ocean water (AOW); surface ocean water (SOW); deep ocean water (DOW); AOW+ (artificial ocean water with BG-11 medium); SOW+ (surface ocean water with BG-11 medium); DOW+ (deep ocean water with BG-11 medium). 
Table 1. The post hoc Bonferroni test results and the comparisons of A. platensis grew in different kinds of oceanwater.

\begin{tabular}{|c|c|c|c|c|c|c|c|c|}
\hline \multicolumn{2}{|c|}{ Oceanwater } & \multirow{2}{*}{$\begin{array}{c}p \text {-value } \\
1.000\end{array}$} & \multicolumn{2}{|c|}{ Oceanwater } & \multirow{2}{*}{$\begin{array}{c}p \text {-value } \\
1.000\end{array}$} & \multicolumn{2}{|c|}{ Oceanwater } & \multirow{2}{*}{$\begin{array}{c}p \text {-value } \\
0.014^{*}\end{array}$} \\
\hline AOW+ & SOW+ & & DOW+ & AOW+ & & sOW & $\mathrm{AOW}+{ }^{*}$ & \\
\hline & DOW+ & 1.000 & & SOW+ & 1.000 & & SOW+ & 1.000 \\
\hline & AOW & 1.000 & & AOW & 1.000 & & DOW+ & 1.000 \\
\hline & SOW $^{*}$ & $0.014^{*}$ & & sow & 1.000 & & AOW & 1.000 \\
\hline & DOW & 0.096 & & DOW & 1.000 & & DOW & 1.000 \\
\hline \multirow[t]{5}{*}{ SOW+ } & AOW+ & 1.000 & AOW & AOW+ & 1.000 & DOW & AOW+ & 0.096 \\
\hline & DOW+ & 1.000 & & SOW+ & 1.000 & & SOW+ & 0.299 \\
\hline & AOW & 1.000 & & DOW+ & 1.000 & & DOW+ & 1.000 \\
\hline & SOW & 0.053 & & sOW & 1.000 & & AOW & 1.000 \\
\hline & DOW & 0.299 & & DOW & 1.000 & & sow & 1.000 \\
\hline
\end{tabular}

Medium: AOW = artificial ocean water; SOW = surface ocean water; DOW = deep ocean water; AOW+ = artificial ocean water with BG-11 medium; SOW+ = surface ocean water with BG-11 medium; DOW+ = deep ocean water with BG-11 medium; ${ }^{*}$ significant at $\alpha=0.05$.

Table 2. Effect of growth media on the generation time for A. platensis.

\begin{tabular}{ccccccc}
\hline Medium $^{1}$ & AOW & SOW & DOW & AOW + & SOW + & DOW + \\
\hline $\begin{array}{c}\text { Generation time (days) } \\
\text { ( } \text { standard deviation) }\end{array}$ & $5.33 \pm 0.079$ & $5.97 \pm 0.54$ & $5.22 \pm 0.38$ & $5.41 \pm 0.18$ & $5.41 \pm 0.15$ & $6.69 \pm 0.77$ \\
\hline
\end{tabular}

Medium: AOW = artificial ocean water; SOW = surface ocean water; DOW = deep ocean water (medium); AOW+ = artificial ocean water with BG-11 medium; SOW+ = surface ocean water with BG-11 medium; DOW+ = deep ocean water with BG-11 medium.

0.007, $0.079 \pm 0.005,0.07 \pm 0.003$, and $0.049 \pm 0.017$ for A. platensis growing in AOW, SOW, DOW, AOW + BG-11, SOW+ BG-11, and DOW+ BG-11, respectively. The A. platensis cultured in DOW medium showed the highest average daily biomass yield.

\section{3. pH Values}

The $\mathrm{pH}$ values in the BG-11-fortified media were slightly higher than in ocean water alone. The $\mathrm{pH}$ values changed from 9.0 to about 9.7 on the fourth day, then gradually declined to 9.1 - 9.4 (Figure 2). We had found turbid conditions occurred in the six different media during the A. platensis growth, so we concluded that the decline of $\mathrm{pH}$ may be due to the precipitation of $\mathrm{CaCO}_{3}(s)$ and $\mathrm{MgCO}_{3}(s)$ in the culture medium.

\section{Discussion}

Pumped DOW is used as a cooling agent after which a small portion is desalinated and used as drinking water. Another small portion is used for making cosmetics or as a medium for culturing probiotics while a large proportion of the remaining DOW is largely unused. The clean and stable water quality of DOW may offer an ideal growth environment for culturing $A$. platensis. This study showed DOW to be a superior culture medium for $A$. platensis as expected. When cultured in DOW without BG-11 medium, A. platensis had the shortest generation time (5.22 \pm 0.38 days) and highest average daily biomass yield ( $0.083 \mathrm{~g} / \mathrm{L}$, dry weight).

Warr et al. [26] have demonstrated that sea salt concentrations of up to $150 \%$ had little effect on the growth of A. platensis. A. platensis showed better growth rate in AOW+ than in SOW probably because the SOW medium lacks some nutrients that were provided through BG-11 supplementation and thus promoted faster growth rates. However, DOW has higher nutrient content hence BG-11 supplementation did not improve the growth rate of $A$. platensis. Instead, A. platensis cultured in the DOW medium had the shortest generation time of 5.22 days. This was longer than the finding of Göksan et al. [24], who reported a 2.15 day generation time for A. platensis M2 growing in greenhouse raceway ponds and Zarrouk medium. We found a clue for this seemingly inconsistent growth performance data. The reason is that our statistical results on growth rates were obtained from the analysis of data not just in different media but also calculated across the fifteen days. If we calculate the generation time by checking the data of the second day to the eighth day, then, the generation times for A. platensis are: $4.93 \pm 0.87$ (day) (grown in AOW), $3.87 \pm 0.07$ (SOW), $2.11 \pm 0.11$ (DOW), $2.77 \pm 0.08$ (AOW+), $3.39 \pm 0.06$ 


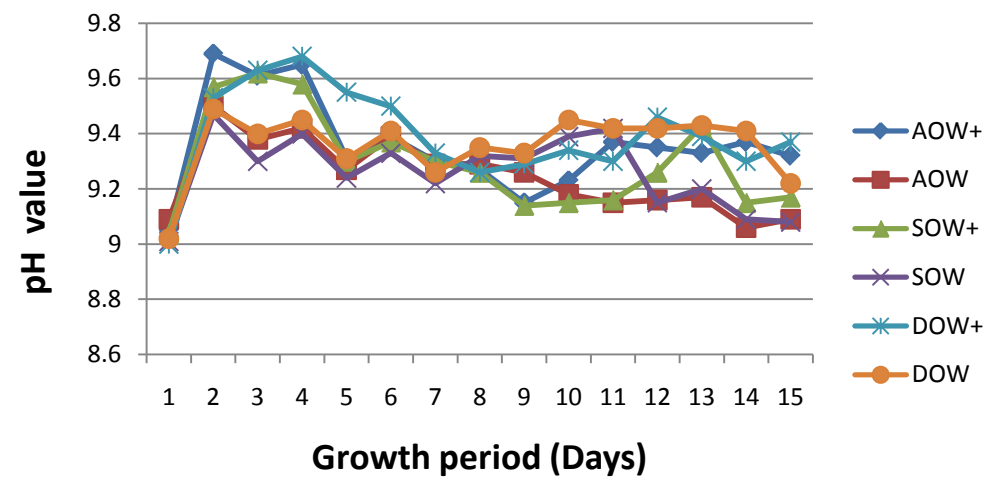

Figure 2. The $\mathrm{pH}$ values of $A$. platensis growing in six different media.

(SOW+), and $3.31 \pm 0.25(\mathrm{DOW}+)$, separately.

It is also reasonable to deduce that the eighth day is the optimum harvesting time. The extra gains in cell density obtained from days nine to 15 are too small to justify the extra week required to attain them. With an initial concentration of A. platensis of $0.2 \mathrm{~g} / \mathrm{L}$ (dry weight), the cell density on the eighth day of growth was $0.8 \mathrm{~g} / \mathrm{L}$ (dry weight) on DOW.

Wu et al. [27] conducted a large scale research on the growth of A. platensis using SOW. They used an unnamed commercial compound fertilizer that contained equal amounts of $\mathrm{N}, \mathrm{P}$, and $\mathrm{K}$, as well as $\mathrm{NaHCO}_{3}, \mathrm{FeSO}_{4}$, and $\mathrm{Na}_{2} \mathrm{CO}_{3}$ in a tubular dialysis membrane to enrich the SOW. They reported harvesting $10.3 \mathrm{~g}$ (dry weight)/ $100 \mathrm{~L}$ per day of $A$. platensis biomass (translating to about $0.103 \mathrm{~g} / \mathrm{L}$ ). In this study average daily yield of $A$. platensis that grew in DOW was $0.083 \pm 0.007 \mathrm{~g} / \mathrm{L}$ whether calculated from the first to eighth day or first to the fifteenth day coincidentally. The growth results reported here are achievable as long as enough light is provided and an automatic culturing system is used. In order to achieve faster growth rates, and therefore, earlier harvesting times, the original seeding concentration should be increased.

Due to the high concentration of $\mathrm{Ca}^{2+}$ and $\mathrm{Mg}^{2+}$ in ocean water [16], the culture media normally become turbid during the A. platensis growth. Adequate $\mathrm{pH}$ maintenance in the culture medium can prevent precipitation of phosphate and other nutrients [28]. The high $\mathrm{pH}$ of the culture media (>9.0) might prevent contamination of growth media by microorganisms [27]. This research can be the basis for designing real-time monitoring and automatic density control [29] of large-scale A. platensis DOW culturing systems and sustaining high biomass production levels.

It is however, important to note that in the long run, the pathogens in SOW may pose another problem in mass algal culture systems. On the other hand, the clean and stable water quality of DOW offers an ideal growth environment for culturing the cyanobacteria with less risk of diseases.

\section{Conclusion}

This is the first study demonstrating that DOW is a superior culture medium for A. platensis growth with the shortest generation time and the highest average daily biomass yield. Moreover, it was found that DOW has enough nutrient content for fast growth of $A$. platensis without supplement. Growing A. platensis will enhance the utilization of DOW.

\section{Acknowledgements}

The authors wish to thank the Industrial and Technology Research Institute, Taiwan, for funding the study. The authors also express their sincere appreciation for Dr. Ru-Mei Jiang of National Taitung University for her assistance with statistical analysis.

\section{References}

[1] Chen, S.H. and Liao, S.H. (2012) Policy on Utilization of Taiwan Deep Ocean Water Resources and Industry-Drive Strategy.

http://www.water.org.tw/simply/twic/PDF/A2-1Policy\%20on\%20Utilization\%20of\%20Taiwan\%20Deep\%200cean\% 


\section{Water\%20Resources\%20and\%20Industry-Drive\%20Strategy.pdf}

[2] Nakasone, T. and Akeda, S. (2012) The Application of Deep Sea Water in Japan. http://www.lib.noaa.gov/retiredsites/japan/aquaculture/proceedings/report28/Nakasone.pdf

[3] Takahashi, M.M. (2005) Research on Deep Ocean Water (DOW) and Its Resource Utilization Developed in Japan. Sino-Japanese DOW Symposium, University of Chinese Culture, Taipei, 1-6.

[4] Gauthier, M.A.P. (2012) Ocean Thermal Energy Conversion and the Utilization of Ocean Water. Encyclopedia of Life Support Systems. http://www.eolss.net/Eolss-SampleALLChapters/aspx

[5] Bae, M.S. and Lee, S.C. (2010) Effect of Deep Sea Water on the Antioxidant Activity and Catechin Content of Green Tea. Journal of Medicinal Plants Research, 4, 1662-1667.

[6] Chen, Y., Li, Y.R., Hsieh, P.F. and Lee, C.S. (2007) Strategies of Developing Deep Ocean Water Industry-Cluster and Value Network Views. Portland International Conference on Management of Engineering and Technology, Portland, 5-9 August 2007, 351-357. http://dx.doi.org/10.1109/picmet.2007.4349349

[7] Ramadan, M.F., Asker, M.M.S. and Ibrahim, Z.K. (2007) Functional Bioactive Compounds and Biological Activities of Spirulina platensis Lipids. Czech Journal of Food Sciences, 26, 211-222.

[8] Ayehunie, S., Belay, A., Baba, T.W. and Ruprecht, R.M. (1998) Inhibition of HIV-1 Replication by an Aqueous Extract of Spirulina platensis (Arthrospira paltensis). Journal of Acquired Immune Deficiency Syndromes, 18, 7-12. http://dx.doi.org/10.1097/00042560-199805010-00002

[9] Ayachi, S.A., Abed, E., Dhifi, W. and Marzouk, B. (2007) Chlorophylls, Proteins and Fatty Acids Amounts of Arthrospira platensis Growing under Saline Conditions. Pakistan Journal of Biological Sciences, 10, 2286-2291. http://dx.doi.org/10.3923/pjbs.2007.2286.2291

[10] Reichert, C.C., Reinehr, C.O. and Costa, A.V. (2006) Semicontinuous Cultivation of the Cyanobacterium Spirulina platensis in a Closed Photobioreactor. Brazilian Journal of Chemical Engineering, 23, 23-28. http://dx.doi.org/10.1590/S0104-66322006000100003

[11] Lodi, A., Binaghi, L., de Faveri, D., Carvalho, J.C.M., Converti, A. and Del Borghi, M. (2005) Fed-Batch Mixtrophic Cultivation of Arthrospira (Spirulina) platensis (Cyanophycea) with Carbon Source Pulse Feeding. Annals of Microbiology, 55, 181-185.

[12] Tokuşoglu, Ö. and Ünal, M.K. (2003) Biomass Nutrient Profiles of Three Microalgae: Spirulina platensis, Chlorella vulgaris, and Isochrisis galbana. Journal of Food Science, 68, 1144-1148. http://dx.doi.org/10.1111/j.1365-2621.2003.tb09615.x

[13] Chronakis, I.S. (2001) Gelation of Editable Blue-Green Algae Protein Isolate (Spirulina platensis Strain Pacifica): Thermal Transitions, Rheological Properties, and Molecular Forces Involved. Journal of Agricultural and Food Chemistry, 49, 888-898. http://dx.doi.org/10.1021/jf0005059

[14] El-Sayed, A.B. and Abdel-Maguid, A.A. (2010) Immobilized-Microalga Scenedesmus sp. for Biological Desalination of Red Sea Water: II. Effect on Macronutrients Removal. Journal of American Science, 6, 637-643.

[15] Sukenik, A. and Shelef, G. (1984) Algal Autoflocculation-Verification and Proposed Mechanism. Biotechnology and Bioengineering, 26, 142-147. http://dx.doi.org/10.1002/bit.260260206

[16] Mary-Leema, J.T., Kirubagaran, R., Vinithkumar, N.V., Dheenan, P.S. and Karthikayylu, S. (2010) High Value Pigment Production from Arthrospira (Spirulina) platensis Cultured in Seawater. Bioresource Technology, 101, 92219227. http://dx.doi.org/10.1016/j.biortech.2010.06.120

[17] Rippka, R., Deruelles, J., Waterbury, J., Herdman, M. and Stanier, R. (1979) Generic Assignments, Strain Histories and Properties of Pure Cultures of Cyanobacteria. Journal of General Microbiology, 111, 1-61. http://dx.doi.org/10.1099/00221287-111-1-1

[18] Wang, T.Y., Liu, H.C. and Lee, Y. (2013) Use of Anthropic Acclimated Spirulina platensis (Arthrospira platensis) Bio-Adsorption in the Treatment of Swine Farm Wastewater. International Journal of Agriculture and Biology, 15, 107-112.

[19] Leone, D.E. (1963) Growth of Chlorella pyrenoidosa in Recycled Medium. Journal of Applied Microbiology, 11, 427429.

[20] Work, K., Havens, K., Sharfstein, B. and East, T. (2005) How Important Is Bacterial Carbon to Planktonic Grazers in a Turbid, Subtropical Lake? Journal of Plankton Research, 4, 357-372. http://dx.doi.org/10.1093/plankt/fbi013

[21] Chen, Y.C. and Lee, M.C. (2012) Double-Power Double-Heterostructure Light-Emitting Diodes in Microalgae, Spirulina platensis and Nannochoropsis oculata, Cultures. Journal of Marine Science and Technology, 20, 233-236

[22] Ungsethapand, T., Peerapornpisal, Y. and Whangchai, N. (2009) Production of Spirulina platensis Using Dry Chick Manure Supplemented with Urea and Sodium Bicarbonate. Maejo International Journal of Science and Technology, 3, 379-387. 
[23] Stal, L.J., Staal, M. and Villbrandt, M. (1999) Nutrient Control of Cyanobacterial Blooms in the Baltic Sea. Aquatic Microbial Ecology, 18, 165-173. http://dx.doi.org/10.3354/ame018165

[24] Göksan, T., Ayşeül, Z. and İlknur, A.K. (2007) The Growth of Spirulina platensis in Different Culture Systems under Greenhouse Condition. Turkish Journal of Biology, 31, 47-52.

[25] Roth, V. (2006) Doubling Time Calculator. http://www.doubling-time.com/compute.php

[26] Warr, S.R.C., Reed, R.H., Chudek, J.A., Foster, R. and Steward, W.D.B. (1985) Osmotic Adjustment in Spirulina platensis. Planta, 163, 424-429. http://dx.doi.org/10.1007/BF00395153

[27] Wu, B., Tseng, C.K. and Xiang, W. (1993) Large-Scale Cultivation of Spirulina in Seawater Based Culture Medium. Botanica Marina, 36, 99-102. http://dx.doi.org/10.1515/botm.1993.36.2.99

[28] Pushparaj, B., Pelosi, E., Carlozzi, P. and Torzillo, G. (1995) Yield and Biochemical Composition of a Marine Cyanobacterium (Nodularia sp.) in Outdoor Culture. Aquatic Microbial Ecology, 9, 13-16. http://dx.doi.org/10.3354/ame009013

[29] Sandnes, J.M., Ringstad, T., Wenner, D., Heyerdahl, P.H., Källqvist, T. and Gislerød, H.R. (2006) Real-Time Monitoring and Automatic Density Control of Large-Scale Microalgal Cultures Using Near Infrared (NR) Optical Density Sensors. Journal of Biotechnology, 122, 209-215. http://dx.doi.org/10.1016/j.jbiotec.2005.08.034 